\title{
Elderly persons with acute pancreatitis - specifics of the clinical course of the disease
}

This article was published in the following Dove Medical Press journal: Clinical Interventions in Aging

\author{
Dorota Koziel' \\ Martyna Gluszek-Osuch' \\ Edyta Suliga' \\ Marek Zak' \\ Stanislaw Gluszek ${ }^{1,2}$ \\ 'Faculty of Medicine and Health \\ Sciences, The Jan Kochanowski \\ University, Kielce, Poland; \\ ${ }^{2}$ Clinic General Oncological and \\ Endocrinological Surgery, Regional \\ Hospital, Kielce, Poland
}

Correspondence: Dorota Koziel

Faculty of Medicine and Health Sciences,

The Jan Kochanowski University, al.

IXWieków Kielc 19, 25-3I7 Kielce,

Poland

Tel +48 693716969

Email dorota.koziel@wp.pl
Background: As may readily be inferred from clinical observations, there is an increasing prevalence of severe acute pancreatitis (SAP) in the elderly, even though the precise nature of the relationship between a patient's age and severity of the disease has not been unequivocally determined to date. This study aimed therefore to investigate the incidence, clinical course, and mortality rate among the elderly patients suffering from acute pancreatitis (AP), as compared to younger ones. Methods: A prospective study, lasting a single calendar year, covered patients with AP successively admitted to hospitals. The final assessment comprised 963 patients. The patients were subsequently divided into three groups corresponding to the three grades of disease severity, based on the Revised Atlanta Classification for Acute Pancreatitis. The actual cause of the disease, its clinical course, results of radiological ultrasonography, computed tomography, and laboratory tests, as well as the duration of hospital stay were assessed in due consideration of patients' age (groups aged $65-79$ years and $\geq 80$ years vs $<65$ years).

Results: Cholelithiasis was determined as the main cause of AP among the older patients (54.08\% and $58.12 \%$ vs $22.46 \% ; P<0.000$ ). Among the oldest patients ( $\geq 80$ years), its course was often significantly more severe, in comparison with the ones under 65 years of age: $14.53 \%$ vs $6.31 \%(P<0.00)$; a phenomenon not observed in the age range 65-79 years, nor among the younger patients $(7.69 \%$ vs $6.31 \% ; P>0.05)$. Moderate AP occurred significantly more often in the younger patients compared to those aged $\geq 80$ years $(16 \%$ vs $8.55 \% ; P<0.00)$, although without any significant differences observed between the group aged 65-79 years and the younger patients $(13.27 \%$ vs $8.55 \%)$. SAP more frequently ended in death among the oldest patients $-11.97 \%$ vs $2.31 \%(P<0.000)$ than in the group aged $65-79$ years $(4.59 \%)$, as compared to the younger groups $(P>0.05)$.

Conclusion: An appreciably higher susceptibility of older patients aged $\geq 80$ years to AP, with cholelithiasis being the main cause that results in high mortality rate, is presently acknowledged a serious diagnostic and therapeutic management challenge to a national healthcare system.

Keywords: acute pancreatitis, elderly patients, predictive factors

\section{Background}

Arguably, population's aging is accompanied by a steadily increasing number of elderly patients suffering from acute pancreatitis (AP). ${ }^{1-3}$ In Poland, the incidence rate of AP is very high and still on the rise among the elderly. ${ }^{1}$ As evidenced, among the individuals aged over 60 years, the incidence rate may be around 150/100,000. ${ }^{1,4}$ Clinical symptoms of acute abdominal pain in the older patients may differ considerably from those in the younger ones. AP is diagnosed when two out of the following three criteria are met: 1) abdominal pain with an acute onset, 2) a threefold increase in the levels of amylase or lipase in blood serum, and 3) results of abdominal imaging are characteristics of AP. ${ }^{5}$ At older age, the symptoms usually occur later, being also 
less specific. The intensity of pain may be lower, whereas a mild increase in amylase activity may well be related to other problems, eg, peptic ulcer or mesenteric ischemia. ${ }^{6}$ Furthermore, older patients usually seek medical assistance rather late, anxious about anticipated loss of independence, likelihood of inadequate care to be provided by the next of kin, or a plain fear of hospitalization or impending death. ${ }^{7}$ The key risk factors for AP are widely acknowledged, with gallstones and alcohol abuse accounting for $80 \%$ of the cases. $^{1,8}$

Less often, the disease is contracted following endoscopic retrograde cholangiopancreatography (ERCP), in the course of hypertriglyceridemia, as an adverse side effect of pharmacotherapy, mucoviscidosis, diabetes, disorders of an autoimmune system, through abdominal injuries, sphincter of Oddi dysfunction, hyperparathyroidism, and other causes. ${ }^{9-13}$ Cholelithiasis is deemed by far the most frequent, particularly among the oldest patients. ${ }^{1}$

In the Western countries, its rate is estimated to be around $13.3 \%$, increasing up to $50.5 \%$ in the case of asymptomatic cholelithiasis. ${ }^{14}$ Also, at an older age, dyed calcified deposits are encountered far more often. Even $50 \%$ of women and $15 \%$ of men aged over 70 years may suffer from gallbladder-related disorders. ${ }^{15}$ A clinical course of AP is usually mild, but in approximately $20 \%$ of the patients it may assume a moderately severe course or even reach a terminal stage. ${ }^{1,9,12}$

The precise nature of the relationship between a patient's age and severity of the disease has not unequivocally been determined as yet. Comparative appraisal of pertinent data, as yielded by these studies published to date, is also appreciably hindered by discrepant values of the upper age limit in the patients admitted to them. A recent study, for instance, highlighted the effect of age on the clinical course of AP to be still pending persuasive elucidation. ${ }^{16}$

This study aimed therefore to investigate the incidence, clinical course, and mortality rate among the elderly patients suffering from AP, as compared to the younger ones.

\section{Methods}

The prospective study covered all patients with AP, successively admitted to all surgical wards (16 wards) in the Świetokrzyskie Region, Poland, within a single calendar year. The study comprised 963 patients recruited from among those admitted to the surgical wards across the province due to AP. Potential subjects were deemed fit for recruitment into the study when two out of the three following criteria were met: 1) abdominal pain with an acute onset, 2) a threefold increase in the levels of amylase or lipase in blood serum, and 3) results of abdominal ultrasonography (USG) imaging are characteristics of AP. ${ }^{5}$ Comprehensive medical documentation of each of the patients was kept in the custody of the attending physicians. Interviews with the patients were aimed at establishing the key risk factors and effective identification of principal complaints. A history of alcohol abuse was diagnosed when a man was established to have consumed $\geq 40 \mathrm{~g}$, and a woman $\geq 20 \mathrm{~g}$, of pure ethanol daily, or very frequently, for the last 5 years, or when a large volume of alcohol was consumed directly prior to contracting the disease. Gallstone etiology was established based on the imaging tests, ie, USG, endoscopic ultrasound (EUS), computed tomography (CT), and magnetic resonance imaging (MRI). Whenever the actual cause of pancreatitis proved impossible to be established, the patients were classified as suffering from idiopathic pancreatitis. Physical examination was aimed at assessing the patients' general health status.

The patients were subsequently divided into three groups corresponding to the three grades of disease severity, based on the Revised Atlanta Classification for Acute Pancreatitis. Mild AP was diagnosed in view of there being no organ dysfunctions, nor local or systemic complications, and moderately severe course was diagnosed against transient ( $<48$ hours) organ dysfunction and/or presence of local or systemic complications, whereas severe course was diagnosed against persistent dysfunction of one or more organs over $>48$ hours. Mild AP was diagnosed in view of there being no organ dysfunctions, nor local or systemic complications, and moderately severe course was diagnosed against transient ( $<48$ hours) organ dysfunction and/or presence of local or systemic complications, whereas severe course was diagnosed against persistent dysfunction of one or more organs over $>48$ hours. The actual cause of the disease, its clinical course, results of radiological (USG and CT) and laboratory tests (hematocrit, hemoglobin [HGB], white blood cells [WBCs], sodium, potassium, C-reactive protein [CRP], creatinine, glucose, Acute Physiology and Chronic Health Evaluation II [APACHE II]), as well as the duration of a hospital stay were assessed in due consideration of the respective age groups (65-79 years and $\geq 80$ years vs $<65$ years).

Patients diagnosed with chronic pancreatitis or pancreatic cancer were excluded from further assessment.

\section{Statistical analysis}

Distribution of quantitative characteristics (age and biochemical blood variables) was investigated in the three specific age groups, ie, $<65$ years, $65-79$ years, and $\geq 80$ years, 
as well as the mean arithmetic values, SD, median, and IQR (Q1-Q3) were calculated. Structural indices were calculated for qualitative characteristics (gender, cause of the disease, severity of clinical course: mild, moderate, severe, and death, as well as for the most frequent concomitant diseases).

In order to assess the probability of the effect of age on the variables characterizing respective study groups, logistic regression analysis was carried out, where the patients under 65 years were a reference group, and OR values and 95\% CI were calculated. Furthermore, in order to estimate the significance of the differences between the mean values in the respective age groups, the following tests were carried out: one-way ANOVA, Kruskal-Wallis one-way ANOVA, and a median test. The respective tests were selected in view of the actual distribution of attendant characteristics and homogeneity of variance.

A logistic regression analysis was performed, and the indicator and $95 \%$ CI were calculated in order to assess the relationship between the demographic variables, causes of AP and any concomitant diseases, as well as to establish the risk of contracting a moderate or a severe form of AP. Two models were presented, ie, a raw model that addressed an independent effect of age, gender, causes of the disease, and concomitant diseases and a multivariate model in which all the above-referenced indicators were given due consideration. All $P$-values presented are two-tailed. $P$-values below 0.05 for the two-tailed test were considered significant. The statistical analysis was carried out with the aid of STATISTICA software package, v. 12.0.

\section{Results}

Within a group of 963 patients with AP, the following three subgroups were designated, ie, Group I: patients aged 18-64 years, 650 persons (67.4\%; 181 women, 469 men), Group II: patients aged 65-79 years, 196 persons (20.4\%; 106 women, 90 men), and Group III: patients aged $\geq 80$ years, 117 persons $(12.2 \%$; 81 women and 36 men). Mean age of older patients (Groups II and III) was $77.0( \pm 7.4)$ years vs $44.0( \pm 12.1)$ years in Group III. There was a higher percentage of women among the older patients, $54.1 \%$ from Group II and $69.2 \%$ from Group III, respectively, vs $27.8 \%$ in the younger Group I. Older patients were suffering from many concomitant diseases, most frequently hypertension, heart disease, diabetes, circulatory failure, atrial fibrillation, degenerative joint disease, chronic obstructive lung disease, and chronic renal failure (Table 1).

The main cause of AP among the older patients was cholelithiasis $(54.1 \%$ in Group II and $58.1 \%$ in Group III vs $22.5 \%$ in Group I; $P<0.000)$. Alcohol abuse was the dominant cause in the younger Group I (36.2\% vs $4.1 \%$ in the age group $65-79$ years and 0 in the age group $\geq 80$ years; $P<0.000)$. In $38.8 \%$ of the older patients aged $65-79$ years and $34.2 \% \geq 80$ years vs $37.9 \%$ of the younger patients, the cause of AP remained unestablished during a hospital stay $(P>0.05)$ and varied in the remaining patients (Table 1). It was established that in the oldest patients from Group III ( $\geq 80$ years), the course of the disease was often significantly more severe $-14.6 \%$ vs $6.3 \%$ in Group I $(P<0.00)$. This was not observed between the groups aged 65-79 years and the younger patients $(7.7 \%$ - Group II vs 6.3\% - Group I; $P>0.05)$. Moderate AP was encountered significantly more often in the younger patients, compared to those aged $\geq 80$ years $(16 \%$ in Group I vs $8.6 \%$ in Group III; $P<0.05)$, whereas in Group II, aged 65-79 years (13.3\%), as compared to Group I, the difference was not significant. Severe AP (SAP) statistically often ended in death in the oldest group of patients (Group III) $12.0 \%$ vs $2.3 \%$ in Group I $(P<0.000)$, but not in Group II, aged $65-79$ years $(4.6 \%)$, as compared to the younger patients from Group I $(P>0.05)$ (Table 1).

Multivariate analysis did not corroborate any significant relationship between age and moderate and severe vs mild cause of the disease $(P>0.05)$.

In the multivariate analysis, chronic diseases had a greater effect on the development of SAP than age: hypertension $P=0.03$, OR 1.48 (1.04-2.11); diabetes mellitus type 1 $P=0.00$, OR 2.95 (1.50-5.80); and circulatory failure $P=0.00$, OR 2.29 (1.36-3.86) (Table 2).

Older patients with mild AP, from Groups II and III, frequently burdened with concomitant diseases, were hospitalized for longer periods, compared to the younger ones with mild AP from Group I $(P<0.05)$; however, in moderate AP and SAP the number of days of a hospital stay in the older patients, particularly the oldest ones, was lesser, ending with death, although statistical significance was not confirmed $(P>0.05)$ (Table 3).

Significant differences between groups of older and younger patients were found, while analyzing the results of the laboratory tests carried out on the first day of hospitalization. Older patients had significantly lower values of hematocrit and $\mathrm{HGB}$, blood urea nitrogen (BUN), and creatinine and a significantly higher level of serum amylase ( $P=0.0000)$. Evaluation of the severity of patients' condition using the APACHE II scale revealed higher mean scores in the group of older patients, ie, 7.49 and 8.99, respectively, compared to the group aged $<65$ years $-3.88(P=0.0000)$ (Table 4). 


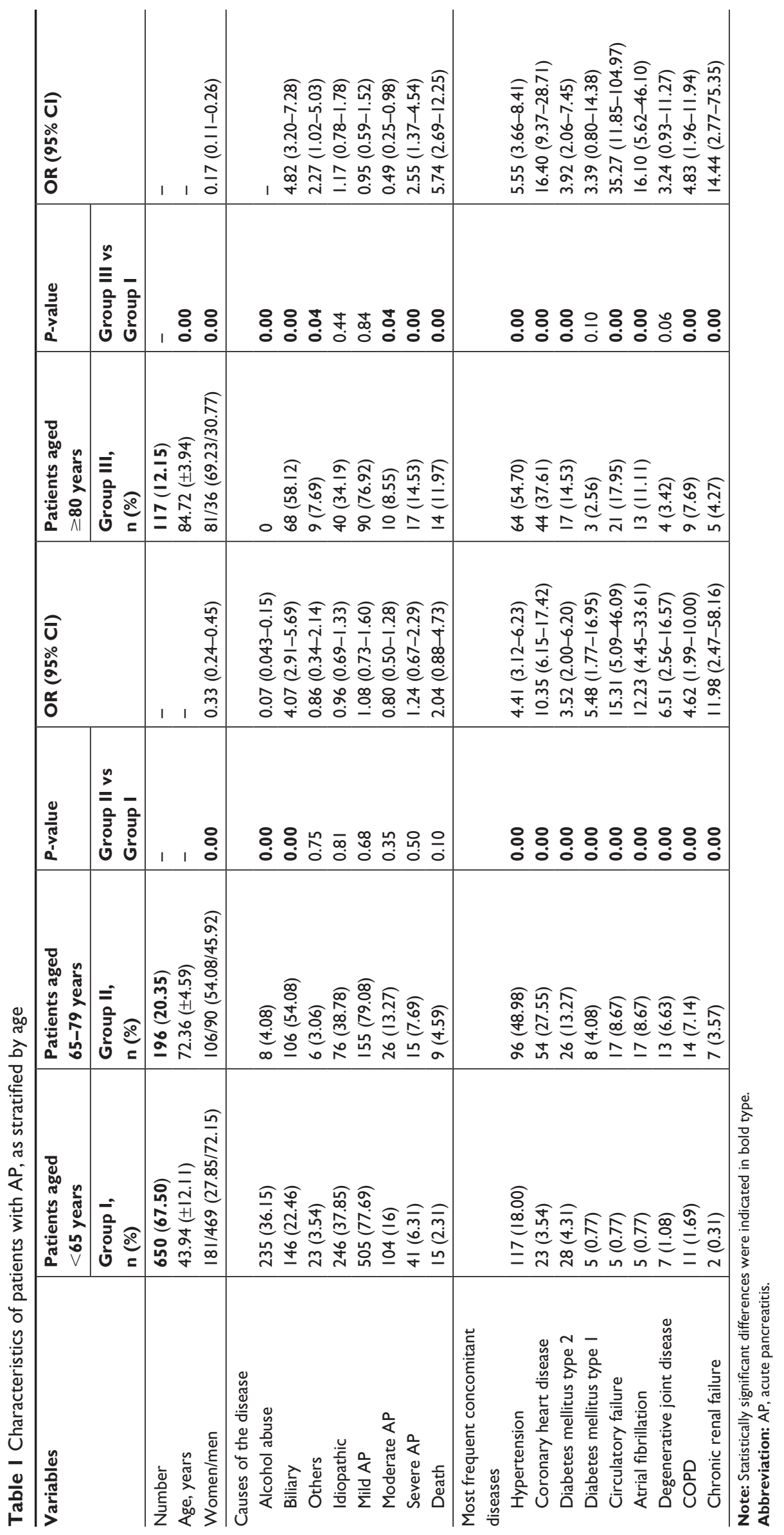


Table 2 Results of bivariate and multivariate analyses, in consideration of a clinical course of AP

\begin{tabular}{|c|c|c|c|c|}
\hline & \multicolumn{2}{|l|}{ Bivariate analysis } & \multicolumn{2}{|c|}{ Multivariate analysis } \\
\hline & OR $(95 \% \mathrm{Cl})$ & $P$-value & OR $(95 \% \mathrm{Cl})$ & $P$-value \\
\hline \multicolumn{5}{|l|}{ Moderate AP vs mild AP } \\
\hline Age, years & $0.99(0.98-1.01)$ & 0.12 & $0.99(0.98-1.01)$ & 0.37 \\
\hline Gender, M/F & $1.27(1.04-1.54)$ & 0.02 & $1.19(0.95-1.50)$ & 0.14 \\
\hline \multicolumn{5}{|l|}{ Causes of the disease } \\
\hline Alcohol abuse & $\mathrm{I} .24(\mathrm{I} .02-\mathrm{I} .5 \mathrm{I})$ & 0.03 & $1.24(0.96-1.60)$ & 0.09 \\
\hline Biliary & $0.83(0.67-1.01)$ & 0.07 & $1.08(0.85-1.39)$ & 0.52 \\
\hline Others & - & - & - & - \\
\hline Idiopathic & $1.43(1.16-1.76)$ & 0.001 & $1.42(1.15-1.76)$ & 0.00 \\
\hline \multicolumn{5}{|c|}{ Most frequent concomitant diseases } \\
\hline Hypertension & $0.98(0.80-1.20)$ & 0.84 & $1.07(0.83-1.37)$ & 0.62 \\
\hline Coronary heart disease & $1.00(0.76-1.3)$ & 0.10 & $1.07(0.75-1.52)$ & 0.70 \\
\hline Diabetes mellitus type 2 & $0.75(0.49-1.15)$ & 0.19 & $0.96(0.63-1.46)$ & 0.85 \\
\hline Diabetes mellitus type I & $1.04(0.48-2.23)$ & 0.92 & $1.21(0.56-2.64)$ & 0.63 \\
\hline Circulatory failure & $074(0.4 I-1.35)$ & 0.33 & $0.99(0.55-1.81)$ & 0.99 \\
\hline Atrial fibrillation & $0.77(0.42-1.40)$ & 0.39 & $0.96(0.50-1.83)$ & 0.90 \\
\hline Degenerative joint disease & $0.95(0.5 \mathrm{I}-\mathrm{I} .76)$ & 0.87 & $1.20(0.6 \mathrm{I}-2.33)$ & 0.60 \\
\hline COPD & $1.04(0.64-1.70)$ & 0.87 & $1.04(0.60-1.82)$ & 0.89 \\
\hline Chronic renal failure & - & - & - & - \\
\hline \multicolumn{5}{|l|}{ Severe AP vs mild AP } \\
\hline Age, years & $1.02(1.01-1.03)$ & 0.01 & $1.01(0.98-1.03)$ & 0.60 \\
\hline Gender, $M / F$ & $1.10(0.86-1.4 I)$ & 0.45 & $1.32(0.98-1.73)$ & 0.09 \\
\hline \multicolumn{5}{|l|}{ Causes of the disease } \\
\hline Alcohol & $1.01(0.76-1.33)$ & 0.95 & $3.14(1.76-5.63)$ & 0.00 \\
\hline Biliary & $\mathrm{I} .02(0.79-\mid .3 \mathrm{I})$ & 0.88 & $2.65(1.56-4.5 I)$ & 0.00 \\
\hline Others & - & - & - & - \\
\hline Idiopathic & $0.32(0.20-0.5 I)$ & 0.00 & $0.76(0.59-0.98)$ & 0.03 \\
\hline \multicolumn{5}{|c|}{ Most frequent concomitant diseases } \\
\hline Hypertension & $1.48(1.16-1.88)$ & 0.00 & $1.48(1.04-2.11)$ & 0.03 \\
\hline Coronary heart disease & $1.19(0.95-1.65)$ & 0.31 & $0.77(0.47-1.25)$ & 0.29 \\
\hline Diabetes mellitus type 2 & $1.23(0.83-1.83)$ & 0.29 & $1.56(0.98-2.47)$ & 0.06 \\
\hline Diabetes mellitus type I & $2.07(1.14-3.75)$ & 0.02 & $2.95(1.50-5.80)$ & 0.00 \\
\hline Circulatory failure & $1.99(1.36-2.91)$ & 0.00 & $2.29(1.36-3.86)$ & 0.00 \\
\hline Atrial fibrillation & $1.40(0.86-2.30)$ & 0.18 & $0.97(0.48-1.95)$ & 0.94 \\
\hline Degenerative joint disease & $1.32(0.7 \mathrm{I}-2.46)$ & 0.38 & $0.84(0.27-2.64)$ & 0.77 \\
\hline COPD & $1.30(0.75-2.23)$ & 0.35 & $1.19(0.62-2.26)$ & 0.60 \\
\hline Chronic renal failure & $2.07(1.14-3.75)$ & 0.02 & $1.28(0.52-3.15)$ & 0.59 \\
\hline
\end{tabular}

Note: Statistically significant differences were indicated in bold type.

Abbreviations: AP, acute pancreatitis; $F$, female; $M$, male.

\section{Discussion}

In recent years, an appreciable increase in morbidity due to AP has been observed among the elderly patients. ${ }^{1,3}$ According to the report summarizing the results of European studies, published in 2017, an increase in morbidity due to AP has been observed among the population aged over 65 years, and especially among the individuals aged over 80 years. ${ }^{3}$ With respect to other patients, the diagnosis was based on

Table 3 Duration of a hospital stay due to AP in the older patients, compared to the younger ones, in due consideration of the severity of the disease

\begin{tabular}{|c|c|c|c|c|c|c|c|}
\hline \multirow[t]{2}{*}{ Variables } & \multicolumn{2}{|c|}{$\begin{array}{l}\text { Hospital stay (days) } \\
\text { Patients aged } \\
<65 \text { years } \\
\end{array}$} & \multicolumn{2}{|c|}{$\begin{array}{l}\text { Hospital stay (days) } \\
\text { Patients aged } \\
\geq 65-79 \text { years }\end{array}$} & \multicolumn{2}{|c|}{$\begin{array}{l}\text { Hospital stay (days) } \\
\text { Patients aged } \\
\geq 80 \text { years }\end{array}$} & \multirow[t]{2}{*}{$P$-value } \\
\hline & $\bar{x}(S D)$ & Me (QI-Q3) & $\bar{x}($ SD) & Me (QI-Q3) & $\bar{x}(\mathrm{SD})$ & Me (QI-Q3) & \\
\hline Mild AP & $6.5 \mathrm{I}(3.6 \mathrm{I})$ & $6.0(4.0-8.0)$ & $8.05(4.11)$ & $7.0(5.0-9.0)$ & $8.62(4.27)$ & $8.0(6.0-10.0)$ & 0.00 \\
\hline Moderate AP & $17.04(12.49)$ & $15.0(7.0-21.0)$ & $14.38(7.37)$ & $12.5(9.0-21.0)$ & $9.90(3.57)$ & | $5.0(7.0-2 \mid .0)$ & $0.03^{\mathrm{a}}$ \\
\hline Severe AP & $15.20(19.94)$ & $9.0(1.0-21.0)$ & $8.40(6.19)$ & $9.0(2.0-13.0)$ & $11.00(12.32)$ & $5.0(3.0-12.0)$ & 0.74 \\
\hline Hospitalization terminated by death & $5.86(1 \mathrm{I} .4 \mathrm{I})$ & $6.0(1.0-9.0)$ & $6.11(6.4 I)$ & $4.0(1.0-9.0)$ & $11.36(13.56)$ & $5.0(2.0-21.0)$ & 0.62 \\
\hline
\end{tabular}

Notes: a Median test. Statistically significant differences were indicated in bold type.

Abbreviations: AP, acute pancreatitis; Me, Median. 


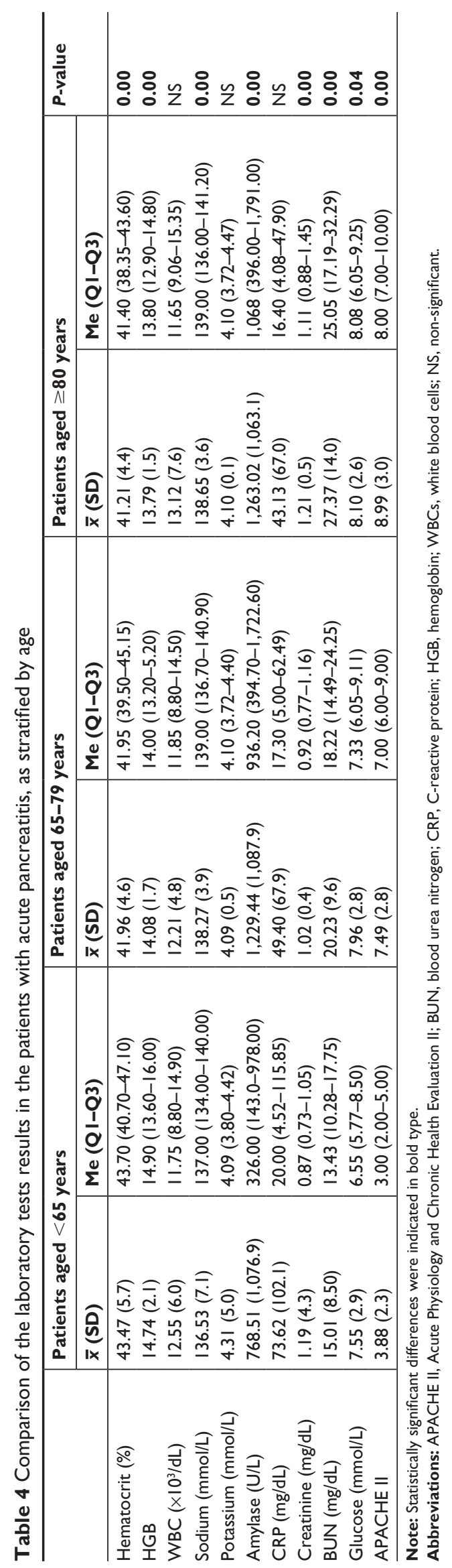

the criteria defined in the Revised Atlanta Classification for Acute Pancreatitis. ${ }^{5}$

The above notwithstanding, it should still be noted at this juncture that the actual symptoms of acute abdominal diseases tend to be far less obvious in the older patients, intensity of pain complaints is lower, symptoms arising from concomitant diseases tend to overlap, and on top of all that, overall effectiveness of communication with the elderly patients is lower, generally owing to a diversity of cognitive disorders. ${ }^{717-19}$

Mean serum amylase levels were significantly higher in the older than that in younger age groups $(1,229.44$ and $1,263.02 \mathrm{U} / \mathrm{L}$ vs $768.51 \mathrm{U} / \mathrm{L} ; P<0.05$ ) of the study subjects, which is believed to be associated with a more severe clinical course of AP in the older patients. In the study by Kim et al, ${ }^{16}$ conducted on a group of 85 older and 142 younger patients, amylase levels did not differ statistically between respective groups, ie, 892.7 vs $663.6 \mathrm{U} / \mathrm{L}(P=0.085)$. In a meta-analysis published in 2017, it was found that amylase had insufficient predictive potential in determining the severity and etiology of AP. ${ }^{20}$ Approximately 1 in 10 patients without AP may be allocated into this group, based on the elevated levels of serum amylase or lipase. ${ }^{21}$ This generally called for greater caution, while setting out to interpret the basic diagnostic tests, especially in a group of the older patients.

The results yielded by this study corroborated the working hypothesis that the main etiologic factor of AP in the older patients was cholelithiasis, as diagnosed in more than half of the study subjects. Similar results had been reported

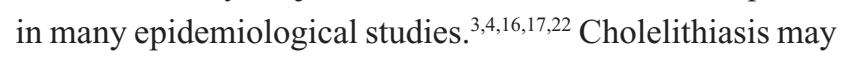
occur in $20 \%$ of the general population ${ }^{23}$ and in one-third of those aged around 70 years.

The age-related changes in biliary metabolism should therefore be looked into as likely potential causative factors, as they in turn stimulate the changes in the lithogenicity of bile, delay in emptying of a gallbladder, apart from being instrumental in widening common bile duct. ${ }^{17,24}$ The widening of common bile duct was confirmed in a large group of patients aged over 70 years; however, the upper limit of the normal value did not exceed $7.6 \mathrm{~mm} .{ }^{25}$ Even up to $50 \%$ of the gallstone cases in the bile duct may be asymptomatic and thus slip away undetected in the imaging tests, despite the application of modern diagnostic techniques. ${ }^{23}$

It should perhaps be highlighted here that cholelithiasis, or an alternative cause of the disease, was not ultimately confirmed in more than $34 \%$ of the patients diagnosed with idiopathic AP, irrespective of age. It follows that actual causes of potential complaints should be sought out comprehensively, 
especially in view of the fact that in older patients the symptoms of gallstones may be far less obvious in their respective manifestations. ${ }^{7,26}$ In the light of the guidelines issued by Polish Pancreatic Club, an early inspection of the bile duct in the course of AP remains controversial. Consideration of ERCP is recommended only in the course of severe, acute biliary pancreatitis. ${ }^{27}$ In the case of its mild form, carrying out cholecystectomy as soon as possible after AP is recommended, ie, during the same hospital stay. In the case of a severe form, postponement of surgical intervention appears to be well justified, until all inflammatory infiltrates are effectively resolved, and the secretion of intra-abdominal fluid arrested. ${ }^{27,28}$

Despite the above-referenced recommendations, an early cholecystectomy is seldom performed, especially in the elderly patients. In the study by Trust et al, ${ }^{29}$ only $57 \%$ of the older patients with mild AP had undergone cholecystectomy during their first hospital stay, and more than half of the remaining patients who had never undergone this procedure were examined by a surgeon. It was also confirmed that mortality in the group who had undergone cholecystectomy was lower than in the one where a surgical intervention was pursued $(0.9 \%$ vs $3.1 \% ; P<0.0001) .{ }^{29}$ Surgical treatment of the bile ducts in older patients is believed to be a safe method of treatment, even in the oldest age group. ${ }^{29,30}$

Elderly patients with AP may present many problems during treatment, due to concomitant diseases. In the group under study, cardiovascular diseases, diabetes, degenerative diseases of the motor system, and COPD were significantly more frequent, compared to the younger patients.

It was confirmed that while referring the patients for a surgical procedure due to cholelithiasis, it was essential to acknowledge that advanced age, complications of diabetes, neurological disorders, liver diseases, weight loss, chronic lung diseases, and congestive circulatory failure may well be the most persuasive contraindications for a surgical intervention. ${ }^{29}$

Some investigators deem age to be an independent risk factor for a severe form of AP. ${ }^{22,31}$ Other studies do not corroborate such an assertion. ${ }^{16,32}$ This study, on the other hand, did manage to establish that age was indeed a risk factor for SAP, but in the patients aged $\geq 80$ years only. Severe course of the disease was noted in $17 / 117$ (14.53\%) patients aged $\geq 80$ years vs $6.31 \%$ in the group of 650 younger patients. It was also duly noted that age appeared of lesser consequence as a causative factor for the development of the severe course of the disease, than various concomitant diseases.

Interestingly enough, local complications related to a moderate course of the disease were more frequently encountered in the group of younger patients, compared to the oldest ones $(P<0.05)$. Xin et al, ${ }^{22}$ in a study of 94 older patients with SAP, also confirmed that they were more often exposed to severe organ failure, even though no differences were noted in the incidence of local complications. In this study, the values of APACHE II were significantly higher in the group of older patients (7.49), especially those aged $\geq 80$ years (8.99), compared to the younger ones (3.88). It was also established that the values of glucose were significantly higher in the older than that in the younger group ( 8.10 vs $7.55 \mathrm{mmol} / \mathrm{L}$ ). Similar observations were reported by $\mathrm{Kim}$ et al, ${ }^{16}$ whereby the values of APACHE II were 9.3 vs $4.9(P<0.001)$. APACHE II $(\geq 5)$ and glucose levels $(\geq 11.1 \mathrm{mmol} / \mathrm{L})$ may well be deemed the predictive factors for the development of severe AP. ${ }^{32}$

High mortality rate was observed among the patients aged $65-79$ years in the course of SAP $(4.59 \% ; P>0.05)$, especially in the group aged $\geq 80$ years $(11.97 \%$ vs $2.31 \%$; $P<0.000$ ). Xin et $\mathrm{al}^{22}$ indicated a mortality rate of $17.0 \%$ among the patients aged $\geq 66$ years vs $5.3 \%$ among those younger. Kim et al did not encounter any differences in the mortality rates between the respective groups (3.5\% vs $0.7 \%$; $P=0.148$ ), whereas Fan et $\mathrm{al}^{33}$ suggested that a high mortality rate among older patients with AP was correlated with various concomitant diseases and was not exclusively the result of an advanced age. The authors of this study actually arrived at the very same conclusion.

Much in line with the findings of other studies, no correlation was established between the patients' age and the duration of an SAP-related hospital stay. ${ }^{16}$ In the group of patients with moderate AP, the younger ones were hospitalized for a significantly longer time $(P<0.05)$, compared to the group with mild AP - those aged over 65 years $(P<0.000)$. Evaluation of own experiences in the treatment of this group highlights the necessity to give due consideration to the attendant differences in the clinical course of AP, as well as to the likely effects of usually numerous, concomitant diseases.

Incidence of AP in the older patients is frequent, especially in the group aged $\geq 80$ years. The principal causative factor is believed to be cholelithiasis, even though in a large group of patients the precise nature of the disease's origins still remains elusive at best. In the older patients, the course of the disease is far more often severe than moderate, accompanied by a high mortality rate, mainly within the group aged $\geq 80$ years. Concomitant diseases are believed to affect both the severe course and an attendant mortality rate in this particular group of patients. As the symptoms of AP in the older patients are far less obvious in their manifestations, 
special caution is therefore advised in their interpretation, as well as with regard to the results of all pertinent laboratory tests.

\section{Conclusion}

An appreciably higher susceptibility of the seniors aged $\geq 80$ years to AP, with cholelithiasis being the main cause, and resultant high mortality rate, is presently acknowledged to be a serious challenge to a national health care system, both in terms of diagnostic procedures and specifically targeted therapeutic management. This is postulated to be urgently addressed in a systemic way.

In line with the findings of this study, all attendant diagnostic procedures should be made appreciably more comprehensive and target-oriented in character, with a view to making them more effective in the early detection of a severe form of the AP.

\section{Ethics approval and consent to participate}

This study was granted ethical approval by the Bioethical Commission (No 1/2012), Faculty of Health Sciences, The Jan Kochanowski University, Kielce. All study protocol procedures were carried out in accordance with the Declaration of Helsinki, and a written informed consent was acquired from all study participants prior to the commencement of the study.

\section{Acknowledgments}

We are very pleased to acknowledge invaluable, handson assistance, and personal dedication contributed by the medical staff of all surgical wards from the Swietokrzyskie Region, Poland, participating in this study in streamlining all procedures entailed in handling and overall management of the source data files. The authors declare that no grants have been received for the pursuit of this study.

\section{Author contributions}

All authors jointly contributed toward data analysis, drafting, and critically revising the manuscript, as well as agree to be held fully accountable for all aspects of the work. All authors reviewed and approved the final version of the manuscript to be published.

\section{Disclosure}

The authors report no conflicts of interest in this work.

\section{References}

1. Głuszek S, Kozieł D. Prevalence and progression of acute pancreatitis in the Świętokrzyskie Voivodeship population. Pol Przegl Chir. 2012; 84(12):618-625.

2. Yadav D, Lowenfels AB. Trends in the epidemiology of the first attack of acute pancreatitis: a systematic review. Pancreas. 2006;33(4): 323-330.

3. Roberts SE, Morrison-Rees S, John A, Williams JG, Brown TH, Samuel DG. The incidence and aetiology of acute pancreatitis across Europe. Pancreatology. 2017;17(2):155-165.

4. Kozieł D, Głuszek S. Epidemiology of acute pancreatitis in Poland selected problems. Medical Studies/Studia Medyczne. 2016;32(1):1-3.

5. Zaheer A, Singh VK, Qureshi RO, Fishman EK. The revised Atlanta classification for acute pancreatitis: updates in imaging terminology and guidelines. Abdom Imaging. 2013;38(1):125-136.

6. Vissers RJ, Abu-Laban RB, McHugh DF. Amylase and lipase in the emergency department evaluation of acute pancreatitis. J Emerg Med. 1999;17(6):1027-1037.

7. Lyon C, Clark DC. Diagnosis of acute abdominal pain in older patients. Am Fam Physician. 2006;74(9):1537-1544.

8. Wang GJ, Gao CF, Wei D, Wang C, Ding SQ. Acute pancreatitis: etiology and common pathogenesis. World J Gastroenterol. 2009;15(12): $1427-1430$.

9. Nesvaderani M, Eslick GD, Vagg D, Faraj S, Cox MR. Epidemiology, aetiology and outcomes of acute pancreatitis: a retrospective cohort study. Int J Surg. 2015;23(Pt A):68-74.

10. Pérez-Mateo M. How we predict the etiology of acute pancreatitis. JOP. 2006;7(3):257-261.

11. Razvodovsky YE. Alcohol consumption and pancreatitis mortality in Russia. JOP. 2014;15(4):365-370.

12. Roberts SE, Akbari A, Thorne K, Atkinson M, Evans PA. The incidence of acute pancreatitis: impact of social deprivation, alcohol consumption, seasonal and demographic factors. Aliment Pharmacol Ther. 2013; 38(5):539-548.

13. Farthing M, Roberts SE, Samuel DG, et al. Survey of digestive health across Europe: Final report. Part 1: the burden of gastrointestinal diseases and the organisation and delivery of gastroenterology services across Europe. United European Gastroenterol J. 2014;2(6): 539-543.

14. Kim SB, Kim KH, Kim TN, et al. Sex differences in prevalence and risk factors of asymptomatic cholelithiasis in Korean health screening examinee: a retrospective analysis of a multicenter study. Medicine. 2017;96(13):e6477.

15. Bingener J, Richards ML, Schwesinger WH, Strodel WE, Sirinek KR. Laparoscopic cholecystectomy for elderly patients: gold standard for golden years? Arch Surg. 2003;138(5):531-535.

16. Kim JE, Hwang JH, Lee SH, et al. The clinical outcome of elderly patients with acute pancreatitis is not different in spite of the different etiologies and severity. Arch Gerontol Geriatr. 2012;54(1):256-260.

17. Ross SO, Forsmark CE. Pancreatic and biliary disorders in the elderly. Gastroenterol Clin North Am. 2001;30(2):531-545.

18. Hendrickson M, Naparst TR. Abdominal surgical emergencies in the elderly. Emerg Med Clin North Am. 2003;21(4):937-969.

19. Kozieł A, Pierzak M, Wychowaniec M, Głuszek S. Analysis of cognitive disorders in older people with diabetes - preliminary study. Medical Studies. 2016;1(1):23-28.

20. Ismail OZ, Bhayana V. Lipase or amylase for the diagnosis of acute pancreatitis? Clin Biochem. 2017;50(18):1275-1280.

21. Rompianesi G, Hann A, Komolafe O, Pereira SP, Davidson BR, Gurusamy KS. Serum amylase and lipase and urinary trypsinogen and amylase for diagnosis of acute pancreatitis. Cochrane Database Syst Rev. 2017;4:CD012010

22. Xin MJ, Chen H, Luo B, Sun JB. Severe acute pancreatitis in the elderly: etiology and clinical characteristics. World J Gastroenterol. 2008;14(16):2517-2521. 
23. Costi R, Gnocchi A, di Mario F, Sarli L. Diagnosis and management of choledocholithiasis in the golden age of imaging, endoscopy and laparoscopy. World J Gastroenterol. 2014;20(37):13382-13401.

24. Perret RS, Sloop GD, Borne JA. Common bile duct measurements in an elderly population. J Ultrasound Med. 2000;19(11):727-730.

25. Benjaminov F, Leichtman G, Naftali T, Half EE, Konikoff FM. Effects of age and cholecystectomy on common bile duct diameter as measured by endoscopic ultrasonography. Surg Endosc. 2013;27(1): 303-307.

26. Zhang ZM, Liu Z, Liu LM, et al. Therapeutic experience of 289 elderly patients with biliary diseases. World J Gastroenterol. 2017;23(13): 2424-2434.

27. Rosołowski M, Lipiński M, Dobosz M, et al. Management of acute pancreatitis (AP) - Polish Pancreatic Club recommendations. Prz Gastroenterol. 2016;11(2):65-72.
28. Working Group IAP/APA Acute Pancreatitis Guidelines. IAP/APA evidence-based guidelines for the management of acute pancreatitis. Pancreatology. 2013;13(4 Suppl 2):e1-e15.

29. Trust MD, Sheffield KM, Boyd CA, et al. Gallstone pancreatitis in older patients: are we operating enough? Surgery. 2011;150(3):515-525.

30. Dubecz A, Langer M, Stadlhuber RJ, et al. Cholecystectomy in the very elderly - is 90 the new 70? J Gastrointest Surg. 2012;16(2):282-285.

31. Compañy L, Sáez J, Martínez J, Aparicio JR, et al. Factors predicting mortality in severe acute pancreatitis. Pancreatology. 2003;3(2): $144-148$.

32. Jin $\mathrm{Z}, \mathrm{Xu} \mathrm{L}$, Wang $\mathrm{X}$, Yang D. Risk factors for worsening of acute pancreatitis in patients admitted with mild acute pancreatitis. Med Sci Monit. 2017;23:1026-1032.

33. Fan ST, Choi TK, Lai CS, Wong J. Influence of age on the mortality from acute pancreatitis. Br J Surg. 1988;75(5):463-466.
Clinical Interventions in Aging

\section{Publish your work in this journal}

Clinical Interventions in Aging is an international, peer-reviewed journal focusing on evidence-based reports on the value or lack thereof of treatments intended to prevent or delay the onset of maladaptive correlates of aging in human beings. This journal is indexed on PubMed Central, MedLine,

\section{Dovepress}

CAS, Scopus and the Elsevier Bibliographic databases. The manuscript management system is completely online and includes a very quick and fair peer-review system, which is all easy to use. Visit http://www.dovepress. $\mathrm{com} /$ testimonials.php to read real quotes from published authors. 